\title{
Dosage Optimization of Treatments Using Population Pharmacokinetic Modeling and Simulation
}

\author{
M. Guidiab, Mona Arab-Alameddine ${ }^{\mathrm{ab}}$, Margalida Rotger ${ }^{\mathrm{c}}$, Manel Aourib ${ }^{\mathrm{b}}$ Amalio Telentic ${ }^{\mathrm{c}}$, \\ Laurent A. Decosterda, Thierry Buclin ${ }^{\mathrm{a}}$, Chantal Csajka ${ }^{\mathrm{ab} *}$, and the Swiss HIV Cohort Study
}

\begin{abstract}
Pharmacokinetic variability in drug levels represent for some drugs a major determinant of treatment success, since sub-therapeutic concentrations might lead to toxic reactions, treatment discontinuation or inefficacy. This is true for most antiretroviral drugs, which exhibit high inter-patient variability in their pharmacokinetics that has been partially explained by some genetic and non-genetic factors. The population pharmacokinetic approach represents a very useful tool for the description of the dose-concentration relationship, the quantification of variability in the target population of patients and the identification of influencing factors. It can thus be used to make predictions and dosage adjustment optimization based on Bayesian therapeutic drug monitoring (TDM). This approach has been used to characterize the pharmacokinetics of nevirapine (NVP) in 137 HIV-positive patients followed within the frame of a TDM program. Among tested covariates, body weight, co-administration of a cytochrome (CYP) 3A4 inducer or boosted atazanavir as well as elevated aspartate transaminases showed an effect on NVP elimination. In addition, genetic polymorphism in the CYP2B6 was associated with reduced NVP clearance. Altogether, these factors could explain $26 \%$ in NVP variability. Model-based simulations were used to compare the adequacy of different dosage regimens in relation to the therapeutic target associated with treatment efficacy. In conclusion, the population approach is very useful to characterize the pharmacokinetic profile of drugs in a population of interest. The quantification and the identification of the sources of variability is a rational approach to making optimal dosage decision for certain drugs administered chronically.
\end{abstract}

Keywords: HIV · Nevirapine · NONMEM · Pharmacokinetics · Population

\section{Population Pharmacokinetic and Pharmacodynamics Analyses}

Drugs with a narrow therapeutic index, important inter-patient and low intra-patient variability, for which a good correlation between drug concentrations and markers of therapeutic success or toxicity has been shown, represent good candidates for therapeutic drug monitoring (TDM). This approach has long been recognized as a very useful tool to bring drug levels into a pre-specified target associated with optimal treatment success. Variability in drug levels under standard

\footnotetext{
Correspondence: Dr. C. Csajka ${ }^{\mathrm{ab}}$

Tel: +41213144263

Fax: +4121314 4266

E-mail: Chantal.Csajka@chuv.ch

aDepartment of Pharmaceutical Sciences

University of Geneva, Geneva

bDivision of Clinical Pharmacology and Toxicology

University Hospital and University of Lausanne

Lausanne

Institute of Microbiology

University Hospital and University of Lausanne

Lausanne
}

dosage regimen is considered as a major determinant of drug response, since it can lead to ineffective drug concentrations or toxic reactions. Of the numerous sources of variability, demographics, environmental, physiopathological factors and more recently genetic polymorphisms have been able to explain part of this variation.

In that respect, population pharmacokinetic and pharmacodynamic modelling has been recognized as an essential component for accurate description of dose-concentration-effect/ toxicity relationships, quantification and explanation of variability in drug concentrations and effects in the target population of patients receiving a drug. Such techniques are ideally suited to describe the distribution of concentration values among patients and to define the target drug exposure to be reached in relation to drug efficacy and toxicity. This approach is a prerequisite for Bayesian treatment individualization, which is of particular importance when potent drugs with a narrow therapeutic index must be administered on the long term.

This approach has been shown to be useful for dosage optimization in the field of HIV therapies, for new targeted oncologic treatment, immunosuppression in transplant recipients, or psychoactive drugs, for which adequate characterization of the concentration-response surface and quantification of variability is of critical importance to improve therapy success while minimizing toxicity. As an example, a population pharmacokinetic study of nevirapine in the treatment of HIV infection is presented.

\section{Variability in Nevirapine Exposure in HIV Positive Patients and in Relation to Treatment Success: An Example of a Population Pharmacokinetic Analysis}

\section{Introduction}

Nevirapine (NVP) was the first nonnucleoside reverse transcriptase inhibitor (NNRTI) to be licensed for clinical use for the treatment of human immunodeficiency virus type 1 (HIV-1) infection. Due to its low cost, NVP remains one of the most widely prescribed antiretroviral drugs in resourcelimited countries. Its pharmacokinetic (PK) profile is characterized by a rapid and almost complete oral absorption and a prolonged disposition phase. ${ }^{[1-4]} \mathrm{NVP}$ 
is mainly metabolized by CYP2B6 and, to a lesser extent by CYP3A4. ${ }^{[2,5-7]} \mathrm{As}$ for other antiretroviral drugs, nevirapine exhibits wide inter-patient variability in its pharmacokinetics, leading to subtherapeutic or toxic levels under standard dosage regimens in a fraction of individuals. Several factors including genetic and nongenetic influences have been reported to affect NVP drug concentrations. ${ }^{[8-16]}$

NVPis used at the recommended dosage regimen of $200 \mathrm{mg}$ twice daily (BID). ${ }^{[5]}$ However, it has been shown that long-term suppression of viral load in HIV-positive patients requires their thorough adherence to therapy, which is easier to obtain with once-daily (QD) dosage regimens.[17-20]

The objective of this observational study was to quantify the pharmacokinetics of NVP in a large cohort of HIV-positive individuals, and to identify factors that might explain variations in drug levels. Coadministered drugs, demographic, clinical characteristics and genetic polymorphisms of $C Y P 3 A 4$ and $C Y P 2 B 6$ were tested as potential influencing factors. Simulations for $400 \mathrm{mg}$ QD and $200 \mathrm{mg}$ BID were performed in order to evaluate the percentage of patients with concentration over the recommended minimum target level of $3000 \mathrm{ng} / \mathrm{mL}$ associated with treatment success. ${ }^{[5]}$

\section{Materials and Methods}

\subsection{Study Population}

A total of 371 patients followed within the frame of a routine TDM program between March 2002 and May 2010 were included. The ethics committees approved the project and all participants gave written informed consent for genetic testing. NVP was administered at doses ranging from $100 \mathrm{mg}$ to $600 \mathrm{mg}$, either QD or BID. A median of one concentration (range 1-14) was collected per patient.

\subsection{Genotyping and Analytical Methods}

Blood samples were collected into lithium heparin or EDTA-K Monovette syringes. Plasma was isolated by centrifugation, inactivated for virus at $60{ }^{\circ} \mathrm{C}$ for $60 \mathrm{~min}$, and stored at $-20{ }^{\circ} \mathrm{C}$ until analysis. Plasma NVP levels were determined by liquid chromatography coupled with tandem mass spectrometry (LC-MS/MS) using an adaptation of the methodology developed in our laboratory. ${ }^{[21]}$ The calibration curves are linear with a lower limit of quantification of 250 $\mathrm{ng} / \mathrm{mL}$. Genotyping was done according to a previously published method. ${ }^{[10]}$ Alleles are designated in concordance with the CYP Allele Nomenclature Committee (http://www.xypalleles.ki.se).

\subsection{Model-based Pharmacokinetic Analysis}

The non-linear mixed effects modeling program (NONMEM version VII, NMTRAN v II $\left.{ }^{[22]}\right)$ was used. This approach allows estimating the population mean of the pharmacokinetic parameters with inter- and intra-individual variability and the influence of available factors on the estimates. Mono- vs. multiple-disposition models were compared. Exponential errors following a lognormal distribution were assumed for the description of the interpatient and intra-patient variability.

Potential covariates influencing the kinetic parameters were incorporated sequentially in the model using linear models for continuous variables or coded as 0 or 1 for categorical covariates; a boundary condition of 1.5 times the upper limit of normal (ULN) was used to recode liver function tests into dichotomous variables. The baseline covariates evaluated were: gender, race, age, body weight, height, liver function tests (alanine amino transferases ALT and aspartate transferases AST) as markers of decreased hepatic function, chronic hepatitis $\mathrm{C}(\mathrm{HCV})$ infection and co-medications (classified as inducers or inhibitors of CYP3A4). For a subset of patients, genetic polymorphisms in $C Y P 3 A 4 * 1 B$ and $C Y P 2 B 6(* 6, * 15, * 18$ and $* 22)$, associated with a decrease/loss in enzymes activity were tested for their impact on NVP clearance CL. Patients were categorized into genotypic groups according to the number of functional alleles, depending if they were carriers of 2 (reference allele; Hom-Ref, fully functional), 1 (heterozygote mutated; HetLOF, partially functional) or unfunctional allele (homozygote mutated; Hom-LOF) for CYP2B6 *6, *15,*18; individuals carrying a gain of function allele $(\mathrm{GOF}=$ increased enzyme activity) for $C Y P 2 B 6 * 22$ were given a score of 3.[23] The influence of genetic polymorphism on NVP CL was evaluated by a rich model that associates a separate fixed effect to each of the genotypic group (GOF, Ref, Het-LOF, Hom-LOF) (Eqn. (1)), as follows:

$$
\mathrm{CL}=\mathrm{CL}_{0} \mathrm{I}_{0}+\mathrm{CL}_{1} \mathrm{I}_{1}+\mathrm{CL}_{2} \mathrm{I}_{2}+\mathrm{CL}_{3} \mathrm{I}_{3}
$$

where $\mathrm{CL}_{0}, \mathrm{CL}_{1}, \mathrm{CL}_{2}$ and $\mathrm{CL}_{3}$ are the typical value of CL for the Hom-LOF, HetLOF, Hom-Ref and GOF groups and $\mathrm{I}_{i}$ is an indicator variable taking the value of 1 if an individual carries the $i$ th genotype, 0 otherwise. Models relating $\mathrm{CL}$ with functional scores $(0,1,2$ or 3 depending on how many alleles were functional) were also tested and compared with the richest possible one (Eqn. (1)) using linear, power and square root functions of the activity scores, expressed by the equations:

$$
\begin{aligned}
& \mathrm{CL}=\mathrm{CL}_{0}+\theta_{1} \times \mathrm{n} \\
& \mathrm{CL}=\mathrm{CL}_{0} \times \theta_{1}^{\mathrm{n}} \\
& \mathrm{CL}=\mathrm{CL}_{0}+\theta_{1} \times \sqrt{n}
\end{aligned}
$$

where $\mathrm{n}=0,1,2$ and 3 represents the functional score and $\theta_{1}$ the average increase per active allele above $\mathrm{CL}_{0}$, which is $\mathrm{CL}$ associated with fully decrease/loss enzyme activity (Hom-LOF).

\subsection{Parameter Estimation and Model Selection}

The data were fitted by use of the first-order conditional method. As a goodness-of-fit statistics, NONMEM ${ }^{\circledR}$ uses an objective function value (OF), which corresponds approximately to -2 log likelihood of the data. The selection between two models is based on graphical diagnostics and on a change in the OF $(\Delta \mathrm{OF})$, which approximates a $\chi^{2}$ distribution. A decrease of the objective function is thus considered statistically significant $(\mathrm{P}<0.05)$ if it exceeds 3.8 for one additional parameter.

\subsection{Model Validation and Simulations}

Model validation was performed by bootstrap resampling method using PsNToolkit (v 3.2.4). ${ }^{[24]}$ Two hundred data sets were reconstructed by re-sampling from the original data. The mean values of the parameters obtained were compared with those estimated from the original data. In addition, the final model with variability was used to simulate 1,000 individuals and to calculate the average concentrations time profile with $95 \%$ prediction intervals under $200 \mathrm{mg}$ BID and $400 \mathrm{mg}$ QD. Concentrations at the end of the dosing intervals $\left(\mathrm{C}_{\min }\right)$ were derived in order to compare obtained values with the threshold of $3^{\prime} 000 \mathrm{ng} / \mathrm{ml}$, which is considered as the value to be targeted for treatment efficacy. ${ }^{[5]}$ Comparisons of average $\mathrm{C}_{\min }$ were performed using a Student t-test. The figures were generated with GraphPad Prism (V 5.0).

\section{Results}

\subsection{Data}

A total of 734 plasma concentrations were included in the population analysis. Measured concentrations ranged between 1065 and $22040 \mathrm{ng} / \mathrm{ml}$. A summary of the study population is presented in Table 1 .

\subsection{Structural Model}

A one-compartment model with firstorder absorption from the gastrointestinal tract was found to describe the data 
Table 1. Characteristics of 371 model-building patients evaluated in the population pharmacokinetics analysis of NVP

\section{Baseline characteristic}

Demographic characteristics

Sex (men/women) (no.)

Median age (yr)

Median body weight $(\mathrm{kg})$

Median height $(\mathrm{cm})$

Ethnicity (no. of patients)

Caucasian

African

Asian

Hispanic

Clinical Chemistry $\left(>1.5 * \mathrm{ULN}^{\mathrm{a}}\right)$

ALT $^{\mathrm{a}}$ (no.)

$\operatorname{AST}^{\mathrm{a}}$ (no.)

Bilirubinemia (no.)

Concomitant medications ${ }^{\mathrm{b}}$

Protease inhibitors

Atazanavir and/or Ritonavir

Amprenavir

Saquinavir

Nelfinavir

Lopinavir

Reverse transcriptase inhibitors

Lamivudine

Zidovudine

Didanosine

Tenofovir

CYP450 inducers

Rifampicine (s)

Rifabutine

Carbamazepine (s)

CYP450 inhibitors

Fluconazole

Fluvoxamine

Chronic Hepatitis

$\mathrm{HCV}^{\mathrm{a}}$

Genetic Polymorphisms ${ }^{\mathrm{c}}$

$\begin{array}{ll}\text { CYP 3A4 } & * 1 \mathrm{~B}(82 \mathrm{p}) \\ \text { CYP 2B6 } & * 6(114 \mathrm{p}) \\ \text { CYP 2B6 } & * 15(82 \mathrm{p}) \\ \text { CYP 2B6 } & * 18(82 \mathrm{p}) \\ \text { CYP 2B } 6 & * 22(82 \mathrm{p})\end{array}$

Model-building patients

$$
\text { Value } \% \text { or range }
$$

$\begin{array}{cc}241 / 130 & 65 / 35 \\ 48 & 24-82 \\ 69 & 40-125 \\ 172 & 145-195\end{array}$

$305 \quad 82$

$51 \quad 14$

103

5

78

38

3

10

0.8

82

3

1

20

63

15

13

12

77

23

4

3

3

20

200

31

67

155

2

2

3

1

83

53

9

18

41

0.5

0.5

0.5

0.8

0.2

22

$4 / 6 / 72$

$5 / 7 / 88$

$8 / 44 / 62$

$7 / 39 / 54$

$0 / 1 / 81$

0/1/99

$0 / 1 / 81$

0/1/99

$0 / 5 / 77 / 0$

0/6/94/0

aULN, upper limit of normal; ALT, alanine aminotransferase; AST, aspartate aminotransferase; HCV chronic hepatitis $\mathrm{C}$. ' Since a careful check of the data file revealed that a single patient can change his therapy with time, the values of the concomitant medications refer to the number of patients taking one of them at least once during the therapy. ${ }^{c}$ The three values refer to the number of Homvariants, Het-variants, Hom-Ref individuals and GOF for CYP2B6²2 characterized for each allelic variant. Het: heterozygous; Hom: homozygous; GOF: gain of function

appropriately. In addition to $\mathrm{CL}$, the assignment of an interpatient variability on the volume of distribution $\mathrm{V}(\Delta \mathrm{OF}=-12.9$ $\mathrm{p}<0.001)$ improved significantly the fit, whereas no variability was observed on the absorption rate constant $\left(k_{a}\right)$, probably due to the limited amount of data characterizing the absorption phase. The PK estimates and the variabilities (CVs) of the population model without any covariates were a CL (CV \%) of $2.97 \mathrm{l} / \mathrm{h}(35 \%)$, a V of $104 \mathrm{l}$ $(58 \%)$ and a $\mathrm{k}_{\mathrm{a}}$ of $1.06 \mathrm{~h}^{-1}$.

\subsection{Non-genetic Covariate Analysis}

Univariate analyses performed using each available covariate identified that body weight $(\Delta \mathrm{OF}=-18.1 \mathrm{p}<0.0001)$, height $(\Delta \mathrm{OF}=-16.4 \mathrm{p}<0.0001), \operatorname{sex}(\Delta \mathrm{OF}$ $=-4.1 \mathrm{p}=0.04), \operatorname{AST}(\Delta \mathrm{OF}=-9.3 \mathrm{p}=$ $0.002)$, chronic hepatitis $\mathrm{C}(\mathrm{HCV})(\Delta \mathrm{OF}$ $=-7.5 \mathrm{p}=0.006)$ co-administration of boosted atazanavir (ATV/RTV) $(\triangle \mathrm{OF}=$ $-16.0 \mathrm{p}<0.0001)$ and $C Y P 3 A 4$ inducers $(\triangle \mathrm{OF}=-10.5 \mathrm{p}=0.001)$ had a significant impact on NVP CL. Multivariate analyses showed that height and sex were correlated to body weight and chronic hepatitis $\mathrm{C}$ was correlated to AST. The final model included body weight, AST, ATV/RTV, and $C Y P 3 A 4$ inducers $(\triangle \mathrm{OF}=-49.5 \mathrm{p}$ $<0.0001$ )

\subsection{Pharmacogenetic Analysis}

Genetic polymorphism in both $C Y P 2 B 6^{*} 6$ and $C Y P 3 A 4^{*} 1 B$ significantly influenced NVP CL in the univariate analyses $(\triangle \mathrm{OF}=-22.4 \mathrm{p}=0.000002$ and $-8.7 \mathrm{p}=0.003$, respectively). The rich model estimated average clearances of $3.37,2.82$ and $1.851 / \mathrm{h}$ in carriers of the CYP2B6*6 Hom-Ref, Het-LOF and HomLOF genotypes, respectively. Models relating $\mathrm{CL}$ with the number of functional alleles indicated that the square root function of the number of functional alleles (Eqn. (4)) best described the relationship between NPV CL and $C Y P 2 B * 6$. A similar trend was observed for the $C Y P 3 A 4 * 1 B$ alleles, yielding a reduction from $3.05 \mathrm{l} / \mathrm{h}$ in Hom-Ref to 2.67 and $1.86 \mathrm{l} / \mathrm{h}$ in Het-LOF and Hom-LOF individuals, respectively. Multivariate analyses revealed that solely $C Y P 2 B 6 * 6$ allelic polymorphism remained statistically significant, in addition to other non-genetic covariates.

The final covariate analysis suggests that CL is increased by $29 \%$ (CI $95 \%$ 6-53\%) on body weight doubling and increased by $36 \%$ (CI 95\% 20-93\%) in case of co-administration of a CYP3A4 inducer. Simultaneous administration of ATV/RTV and elevated AST on the other hand, reduced CL by $16 \%$ (CI $95 \%$ $5-26 \%$ ) and $29 \%$ (CI 95\% 14-44\%), respectively. Individuals carrying 1 or 2 loss of function of the CYP2B $6 * 6$ alleles have a decrease of $16 \%$ (CI 95\% 5-27\%) and $45 \%$ (CI 95\% 32-58\%) resp. in NVP $\mathrm{CL}$ compared to individuals carrying the fully functional allele. The final model parameters' estimates, together with their bootstrap estimations, are summarized in Table 2. Fig. 1 shows the concentrationtime plots of NVP after either $200 \mathrm{mg}$ BID or $400 \mathrm{mg}$ QD regimens, together with the $95 \%$ prediction intervals. Fig. 2 depicts the decrease in NPV CL associated with $C Y P 2 B 6^{*} 6$ genetic polymorphism in the presence or not of an elevation of AST for a $70 \mathrm{~kg}$ person, assuming no coadministration of a CYP3A4 inducer.

\subsection{Simulations of Dosage \\ Regimens}

Simulations based on the final PK parameters without covariates predicted an average concentration at the end of the dosing interval $\left(\mathrm{C}_{\min }\right)$ of $5204 \mathrm{ng} / \mathrm{ml}(95 \%$ PI: 1994-11545 $\mathrm{ng} / \mathrm{ml}$ ) for the $200 \mathrm{mg}$ BID 12 hours after drug intake and of 4277 $\mathrm{ng} / \mathrm{ml}$ (95\% PI: $1231-9915 \mathrm{ng} / \mathrm{ml})$ for the $400 \mathrm{mg}$ QD dosage regimen 24 hours after drug intake. While taking into account 
Table 2. Final population pharmacokinetic/pharmacogenetic parameter estimates of NVP and their bootstrap evaluations

\begin{tabular}{|c|c|c|c|c|c|c|c|c|}
\hline \multirow[b]{2}{*}{ Parameter } & \multicolumn{4}{|c|}{ Population mean } & \multicolumn{4}{|c|}{ Bootstrap evaluation } \\
\hline & Estimate & $\mathrm{SE}^{\mathrm{a}}[\%]$ & $\operatorname{IIV}^{\mathrm{b}}[\%]$ & $\mathrm{SE}^{\mathrm{c}}[\%]$ & Estimate & $\mathrm{SE}^{\mathrm{a}}[\%]$ & $\operatorname{IIV}^{\mathrm{b}}[\%]$ & $\mathrm{SE}^{\mathrm{c}}[\%]$ \\
\hline \multicolumn{9}{|c|}{ Model for the entire population $n=371$} \\
\hline CL (1/h) & 3.05 & 2 & 32 & 36 & 3.06 & 2 & 32 & 35 \\
\hline$\theta_{\mathrm{BW}}$ & 0.39 & 25 & & & 0.40 & 24 & & \\
\hline$\theta_{\text {ATV/RTV }}$ & -0.16 & 29 & & & -0.16 & 28 & & \\
\hline$\theta_{\mathrm{INDC}}$ & 0.36 & 79 & & & 0.31 & 77 & & \\
\hline$\theta_{\mathrm{AST}}$ & -0.13 & 38 & & & -0.13 & 38 & & \\
\hline $\mathrm{V}(1)$ & 95.9 & 11 & 56 & 53 & 96.3 & 12 & 56 & 55 \\
\hline $\mathrm{k}_{\mathrm{a}}\left(\mathrm{h}^{-1}\right)$ & 0.99 & 21 & & & 1.00 & 22 & & \\
\hline$\sigma(\mathrm{CV} \%)^{\mathrm{d}}$ & 26 & $31^{\mathrm{c}}$ & & & 25 & $32^{c}$ & & \\
\hline \multicolumn{9}{|c|}{ Model for the subpopulation characterized for CYP2B6*6 genetic polymorphisms $n=114$} \\
\hline $\mathrm{CL}(1 / \mathrm{h})^{\mathrm{e}}$ & 1.81 & 10 & 26 & 58 & 1.82 & 12 & 24 & 65 \\
\hline$\theta_{C Y P 2 B 6^{*} \sigma^{\mathrm{f}}}$ & 1.07 & 14 & & & 1.06 & 17 & & \\
\hline$\theta_{\mathrm{BW}}$ & 0.29 & 41 & & & 0.29 & 44 & & \\
\hline$\theta_{\mathrm{ATV} / \mathrm{RTV}}$ & -0.16 & 34 & & & -0.16 & 42 & & \\
\hline$\theta_{\text {INDC }}{ }^{g}$ & 0.36 & - & & & 0.36 & - & & \\
\hline$\theta_{\mathrm{AST}}$ & -0.29 & 26 & & & -0.27 & 32 & & \\
\hline V (1) & 80.4 & 22 & 58 & 71 & 82.4 & 30 & 62 & 79 \\
\hline $\mathrm{k}_{\mathrm{a}}\left(\mathrm{h}^{-1}\right)$ & 0.79 & 32 & & & 0.83 & 44 & & \\
\hline$\sigma(\mathrm{CV} \%)^{\mathrm{d}}$ & 22 & $43^{c}$ & & & 22 & $46^{c}$ & & \\
\hline
\end{tabular}

$\mathrm{CL}$, mean apparent clearance; $\mathrm{V}$, mean apparent volume of distribution; $\mathrm{k}_{\mathrm{a}}$, mean absorption rate constant; BW, body weight; ATV/RTV, administration of atazanavir and ritonavir; INDC, CYP3A4 inducers; AST, aspartate aminotransferase. aStandard errors of the estimates (SE) are defined as SE/ estimate and are expressed as percentages. 'Interindividual variability defined as CVs [\%]. 'Standard errors of the coefficient of variations, calculated as (SE/estimate) ${ }^{\wedge} 0.5$, are expressed as percentages. ${ }^{\mathrm{d}}$ Residual intrapatient variability, expressed as a CV [\%]. ${ }^{\circ} \mathrm{CL}$ for the CYP2B6 6 Hom-LOF pati-

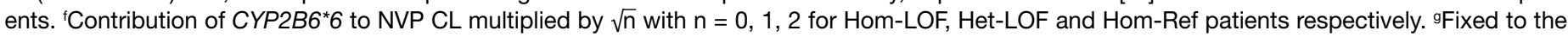
estimates obtained in the whole population.
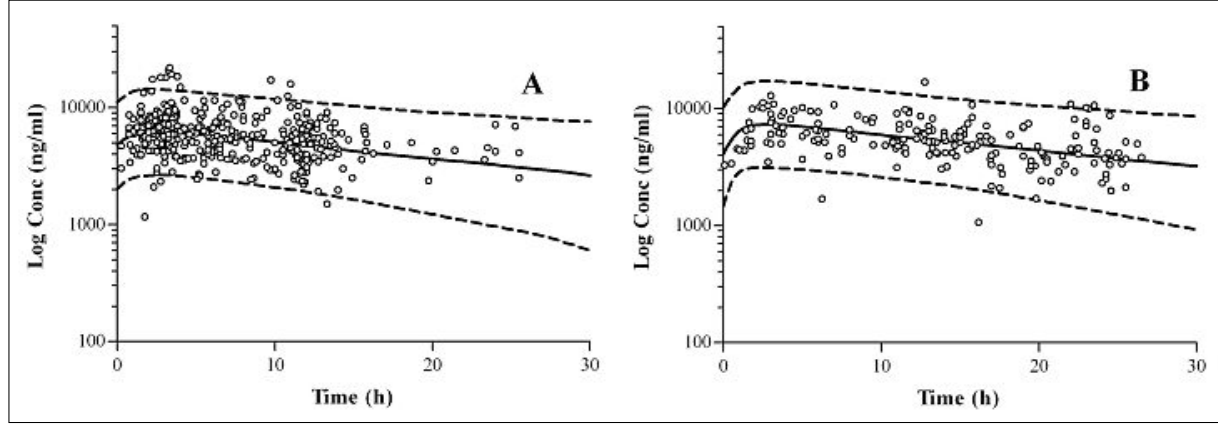

Fig. 1. Plasma NVP concentration-time plots of patients receiving $200 \mathrm{mg} B I D(A)$ and $400 \mathrm{mg}$ QD (B) dose of NVP. Circles represent patient samples; solid line, average population prediction value; dashed lines, 95\% prediction intervals.

the variability in the PK, $16 \%$ of patients after $200 \mathrm{mg}$ BID are expected to have a $\mathrm{C}_{\min }$ under the recommended minimum target level of $3000 \mathrm{ng} / \mathrm{ml}$, whereas $30 \%$ would be below this target after $400 \mathrm{mg}$ QD. Average $\mathrm{C}_{\min }$ was $8092 \mathrm{ng} / \mathrm{ml}$ (95\% PI: $2800-17974 \mathrm{ng} / \mathrm{ml}$ ) after $400 \mathrm{mg}$ QD in individuals with no functional $C Y P 2 B 6 * 6$ allele, with only $3 \%$ of individuals with $\mathrm{C}_{\text {min }}$ below the target level of $3000 \mathrm{ng} / \mathrm{ml}$.

\section{Discussion}

NVP is characterized by high interindividual variability, of which $26 \%$ could be explained by body weight, coadministration of CYP3A4 inducers and inhibitors, elevated AST level and $C Y P 2 B 6 * 6$ polymorphisms. The presence of such factors might lead to sub-therapeutic drug levels in some individuals and are thus important to be identified in order to optimize drug regimens. PK estimates are in good accordance with previously published reports. ${ }^{[8,9,12,14,15]}$ Body weight has been shown to be associated with NVP CL in several studies. ${ }^{[8,12,15]}$ As expected and previously reported, concomitant administration of strong CYP3A4 inducers affects NVP exposure. ${ }^{[25]}$ Although co- administration of ATV/RTV with NVP is not recommended in antiretroviral therapy, ${ }^{[26]} 17 \%$ of our study participants were taking both drugs. A small $16 \%$ reduction in NVP elimination was observed, which is of limited clinical relevance with regard to NVP. Similarly to our results, elevated AST level has been previously reported to modestly decrease NPV CL. ${ }^{[8]}$ It remains however unclear whether the elevation of hepatic enzymes is the cause or the consequence of high NVP levels, since NVP is a hepatotoxic drug. Among all tested variables, genetic polymorphism in $C Y P 2 B 6^{*} 6$ had the most profound impact on NVP elimination. ${ }^{[10,11,13-16]}$ In our population, it explained $13 \%$ of NVP variability. As already described for efavirenz, ${ }^{[23]}$ the use of an activity score associated with the number of functional alleles could describe the influence of this genetic polymorphism using a square root function, suggesting that the enzyme activity was almost totally maintained in carriers of one functional allele, whereas it was markedly reduced in carriers of the homozygote mutation. This phenomenon suggests adaptive mechanisms, possibly through the activation of nuclear receptors. [27] Several studies have compared the 


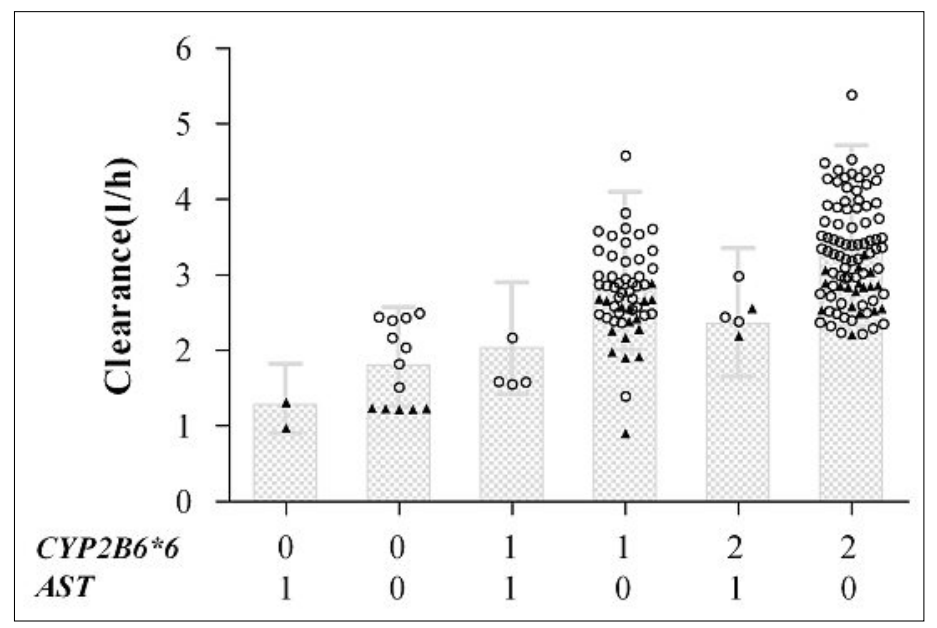

Fig. 2. Individual (open circles) and average predicted clearences (bars) with 90\% population prediction intervals for each combination of elevated aspartate aminotransferase (AST) (coded as 1 when AST > 1.5*upper limit of normal, 0 otherwise) and CYP2B6* 6 functional alleles (coded as 2 for homozygote reference alleles, 1 for heterozygote mutated and 0 for homozygote mutated alleles, for a $70 \mathrm{~kg}$ person. The triangles represent $\mathrm{CL}$ associated to patients taking ATV/RTV in addition to the other depicted covariates.

once- and the twice-daily nevirapine immediate-release dosage regimens in order to identify the dose that optimizes efficacy, while improving adherence and minimizing toxicity. Despite the absence of a clear relationship between drug exposure and toxicity, ${ }^{[28-33]}$ some evidence suggests that the $400 \mathrm{mg}$ QD regimen might be associated with an increased risk of hypersensitivity reactions leading to treatment interruption. ${ }^{[33,34]}$ Our simulations indicate that concentration exposure is less frequently maintained over the target trough level with the 400 mg QD regimen than with the currently recommended $200 \mathrm{mg}$ BID regimen. However, in the subpopulation of individuals carrying the mutations in the CYP2B6*6 genotype, the oncedaily therapeutic scheme performs better, but might be related to an increased risk of toxicity.

In conclusion, NVP PK is influenced by several environmental and physiopathological factors and by $C Y P 2 B 6^{*} 6$ genetic polymorphisms that should be accounted for in dosage individualization. Simulations suggest that the $400 \mathrm{mg}$ once daily dosage regimen would provide sub-optimal drug levels according to target concentrations in a higher number of patients than the $200 \mathrm{mg}$ twice-daily regimen. The recent approval by the FDA of an extendedrelease formulation has been shown to circumvent this issue. Dose adjustment in a sub-population of patients showing high exposure in relation with genetic traits may be considered as a dosing strategy with the potential to reduce both costs and toxicity.

\section{Acknowledgments}

The authors are thankful to the Vital-it platform of the Swiss Institute of Bioinform -atics for providing the computational resources for the population PK analysis.

Received: March 2, 2012

[1] S. H. Cheeseman, S. E. Hattox, M. M McLaughlin, R. A. Koup, C. Andrews, C. A. Bova, J. W. Pav, T. Roy, J. L. Sullivan, J. J. Keirns, Antimicrob. Agents Ch. 1993, 37, 178.

[2] D. Havlir, S. H. Cheeseman, M. McLaughlin, R. Murphy, A. Erice, S. A. Spector, T. C. Greenough, J. L. Sullivan, D. Hall, M. Myers, et al., J. Infect. Dis. 1995, 171, 537.

[3] R. Murphy, J. S. Montaner, Exp. Opin. Invest. Drugs 1996, 5, 1183.

[4] M. J. Lamson, J. P. Sabo, T. R. MacGregor, J. W. Pav, L. Rowland, A. Hawi, M. Cappola, P. Robinson, Biopharm. Drug Dispos. 1999, 20, 285.

[5] Department of Health and Human Services, 'Panel on Antiretroviral Guidelines for Adults and Adolescents. Guidelines for the use of antiretroviral agents in HIV-1-infected adults and adolescents', January 10, 2011, available from: http://www.aidsinfo.nih.gov/ ContentFiles/AdultandAdolescentGL.pdf.

[6] P. Riska, M. Lamson, T. MacGregor, J. Sabo, S. Hattox, J. Pav, J. Keirns, Drug Metab. Dispos. 1999, 27, 895.

[7] D. A. Erickson, G. Mather, W. F. Trager, R. H Levy, J. J. Keirns, Drug Metab. Dispos. 1999, 27, 1488.

[8] M. M. de Maat, A. D. Huitema, J. W. Mulder, P. L. Meenhorst, E. C. van Gorp, J. H. Beijnen, $B r$. J. Clin. Pharmacol. 2002, 54, 378.

[9] B. S. Kappelhoff, F. van Leth, T. R. MacGregor J. Lange, J. H. Beijnen, A. D. Huitema, Antivir. Ther. 2005, 10, 145.

[10] M. Rotger, S. Colombo, H. Furrer, G. Bleiber, T. Buclin, B. L. Lee, O. Keiser, J. Biollaz, L. Decosterd, A. Telenti, Pharmacogenet. Genom. 2005, 15,1 .

[11] A. Saitoh, E. Sarles, E. Capparelli, F. Aweeka, A. Kovacs, S. K. Burchett, A. Wiznia, S. Nachman, T. Fenton, S. A. Spector, AIDS 2007, 21, 2191.

[12] J. Molto, M. Valle, C. Miranda, S. Cedeno, J. Miranda, J. R. Santos, E. Negredo, J. Vilaro, J. Costa, B. Clotet, J. Antimicrob. Chemoth. 2008, 62,784 .

[13] T. Mahungu, C. Smith, F. Turner, D. Egan, M. Youle, M. Johnson, S. Khoo, D. Back, A. Owen, HIV Med. 2009, 10, 310.
[14] M. Chou, J. Bertrand, O. Segeral, C. Verstuyft, L. Borand, E. Comets, C. Le Tiec, L. Becquemont, V. Ouk, F. Mentre, A. M. Taburet, Antimicrob. Agents Ch. 2010, 54, 4432.

[15] A. Schipani, C. Wyen, T. Mahungu, H. Hendra, D. Egan, M. Siccardi, G. Davies, S. Khoo, G. Fatkenheuer, M. Youle, J. Rockstroh, N. H. Brockmeyer, M. A. Johnson, A. Owen, D. J. Back, J. Antimicrob. Chemoth. 2011, 66, 1332.

[16] S. Swaminathan, G. Ramachandran, H. K Agibothu Kupparam, V. Mahalingam, L. Soundararajan, B. Perumal Kannabiran, P. G. Navaneethapandian, I. Shah, R. Karunaianandham, R. Sikhamani, J. Antimicrob. Chemoth. 2011, 66, 1354.

[17] J. L. Casado, R. Sabido, M. J. Perez-Elias, A Antela, J. Oliva, F. Dronda, B. Mejia, J. Fortun, Antivir. Ther. 1999, 4, 157.

[18] R. H. Haubrich, S. J. Little, J. S. Currier, D. N. Forthal, C. A. Kemper, G. N. Beall, D. Johnson, M. P. Dube, J. Y. Hwang, J. A. McCutchan, AIDS 1999, 13, 1099.

[19] D. L. Paterson, S. Swindells, J. Mohr, M. Brester, E. N. Vergis, C. Squier, M. M. Wagener, N. Singh, Ann. Intern. Med. 2000, 133, 21.

[20] M. de Bruin, W. Viechtbauer, H. P. Schaalma, G. Kok, C. Abraham, H. J. Hospers, Arch. Intern. Med. 2010, 170, 240.

[21] S. Colombo, A. Beguin, A. Telenti, J. Biollaz, T. Buclin, B. Rochat, L. A. Decosterd, $J$. Chromatogr. B 2005, 819, 259.

[22] S. L. Beal, L. B. Sheiner, A. Boeckmann, R. J. Bauer, NONMEM User's Guides (1989-2009), 2009, Icon Development Solutions: Ellicot City, MD, USA.

[23] M. Arab-Alameddine, J. Di Iulio, T. Buclin, M. Rotger, R. Lubomirov, M. Cavassini, A. Fayet, L. A. Decosterd, C. B. Eap, J. Biollaz, A. Telenti, C. Csajka, Clin. Pharmacol. Ther 2009, 85,485 .

[24] L. Lindbom, P. Pihlgren, E. N. Jonsson, Comput. Meth. Progr. Bio. 2005, 79, 241.

[25] D. Elsherbiny, K. Cohen, B. Jansson, P. Smith, H. McIlleron, U. S. Simonsson, Eur. J. Clin. Pharmacol. 2009, 65, 71

[26] 'Reyataz Prescribing Information, BristolMyers Squibb Co', February 2011.

[27] S. R. Faucette, T. C. Zhang, R. Moore, T. Sueyoshi, C. J. Omiecinski, E. L. LeCluyse, M. Negishi, H. Wang, J. Pharmacol. Exp. Ther. 2007, 320, 72.

[28] R. P. G. van Heeswijk, A. I. Veldkamp, J. W. Mulder, P. L. Meenhorst, F. Wit, J. M. A Lange, S. A. Danner, N. A. Foudraine, M. O. Kwakkelstein, P. Reiss, J. H. Beijnen, R. M. W. Hoetelmans, AIDS 2000, 14, F77.

[29] A. I. Veldkamp, G. J. Weverling, J. M. A. Lange, J. S. G. Montaner, P. Reiss, D. A. Cooper, S. Vella, D. Hall, J. H. Beijnen, R. M. W. Hoetelmans, AIDS 2001, 15, 1089.

[30] T. E. de Vries-Sluijs, J. P. Dieleman, D. Arts, A D. Huitema, J. H. Beijnen, M. Schutten, M. E. van der Ende, Clin. Pharmacokinet. 2003, 42, 599.

[31] B. S. Kappelhoff, A. D. Huitema, F. van Leth, P. A. Robinson, T. R. MacGregor, J. M. Lange, J. H. Beijnen, HIV Clin. Trials 2005, 6, 254

[32] B. S. Kappelhoff, F. van Leth, P. A. Robinson, T. R. MacGregor, E. Baraldi, F. Montella, D E. Uip, M. A. Thompson, D. B. Russell, J. M. Lange, J. H. Beijnen, A. D. Huitema, Antivir. Ther 2005, 10, 489.

[33] F. Van Leth, B. S. Kappelhoff, D. Johnson, M. H. Losso, A. Boron-Kaczmarska, M. S. Saag, J. M. Livrozet, D. B. Hall, J. Leith, A. D. R. Huitema, F. W. Wit, J. H. Beijnen, J. M. A. Lange, N. N. S. Grp, AIDS Res. Hum. Retrov. 2006, 22, 232.

[34] A. Calmy, N. Vallier, A. Nguyen, J. M. Lange, M. Battegay, F. de Wolf, P. Reiss, V. D. Lima, B Hirschel, R. S. Hogg, B. Yip, J. S. Montaner, F. W. Wit, Antivir. Ther 2009, 14, 931. 